\title{
An anaerobic digester with microbial electrolysis cell enhances relative abundance of methylotrophic methanogens in bulk solution
}

\author{
Jun-Gyu Park ${ }^{1}$, Beom Lee ${ }^{2,3}$, Ui-Jung Lee ${ }^{2}$, Hang-Bae Jun ${ }^{+}$ \\ ${ }^{1}$ Department of Advanced Energy Engineering, Chosun University, Gwangju 61452, Republic of Korea \\ ${ }^{2}$ Department of Environmental Engineering, Chungbuk National University, Cheongju 28644, Republic of Korea \\ ${ }^{3}$ Nature Engineering Co., Ltd, Cheongju 28644, Republic of Korea
}

\begin{abstract}
The microbial communities and operational performances of a conventional anaerobic digester (AD) and an $\mathrm{AD}$ combined with microbial electrolysis cells (ADMEC) were investigated. Primary sludge and waste-activated sludge were used as substrates, and next-generation sequencing (NGS) techniques were used to analyze the microbial characteristics. The results show that ADMEC can achieve a faster stabilization rate, higher organic decomposition, and methane production performance than $\mathrm{AD}$. After both the ADMEC and AD reached a steady state, microbial results revealed that Methanobacterium beijingense and Methanosaeta concilii were the dominant methane-generating archaeal species in AD. In ADMEC, the relative abundance of methylotrophic methanogens (Thermoplasmata class), which has higher methane productivity than other methanogens, is significantly improved. For bacterial communities, an improved relative abundance of the Cloacamonas phylum, which is involved in amino acid fermentation, and in the Erysipelotrichi class, which grows well in environments with high organic concentrations, was observed in ADMEC. In summary, $\mathrm{ADMEC}$ is more efficient than $\mathrm{AD}$ because organic degradation and methanol production accelerated by bioelectrochemical reactions occur in ADMEC, leading to a favorable environment for the growth of methylotrophic methanogens in bulk solution.
\end{abstract}

Keywords: Anaerobic digestion, Methylotrophic methanogen, Microbial electrolysis cell, Mixed sludge, 454-pyrosequencing

\section{Introduction}

Anaerobic digesters (ADs) are bioreactors that decompose organic matter and produce biogas through step reactions that comprise hydrolysis, acidogenesis, and methanogenesis stages [1]. Hydrolysis, the first stage in the process, is a biodegradation reaction in which insoluble solids are broken down into monomers or dimers [2], which are in turn decomposed into volatile fatty acids (VFAs) in the acidogenesis stage [3]. In this second stage, propionic acid and butyric acid, which are intermediates during the acid production reaction, are further fermented to form acetic acid during the acetogenesis process [4]. In the final methane production stage, the acids generated during acidogenesis are converted into methane. Two-thirds of the total methane is produced from fermentation products of alcohol, such as acetic acid (Eq. (1)) or $\mathrm{CH}_{3} \mathrm{OH}$ (Eq. (2)), and the remaining one-third is pro- duced using $\mathrm{H}_{2}$ and $\mathrm{CO}_{2}$ as electron donors and electron acceptors, respectively (Eq. (3); [5]).

Acetoclastic methanogenesis:

$$
\mathrm{CH}_{3} \mathrm{COOH} \rightarrow \mathrm{CH}_{4}+\mathrm{CO}_{2}
$$

Methylotrophic methanogenesis:

$$
4 \mathrm{CH}_{3} \mathrm{OH} \rightarrow 3 \mathrm{CH}_{4}+\mathrm{CO}_{2}+2 \mathrm{H}_{2} \mathrm{O}
$$

Hydrogenotrophic methanogenesis:

$$
\mathrm{CO}_{2}+4 \mathrm{H}_{2} \rightarrow \mathrm{CH}_{4}+2 \mathrm{H}_{2} \mathrm{O}
$$

$\mathrm{AD}$ produces biogas, reduces organic matter, stabilizes sludge, and removes harmful bacteria [6]; however, it is limited by several operational issues, such as slow growth of methane-producing archaea, low digestive efficiency, long hydraulic retention time, the
This is an Open Access article distributed under the terms of the Creative Commons Attribution Non-Commercial License (http://creativecommons.org/licenses/by-nc/3.0/) which permits unrestricted non-commercial use, distribution, and reproduction in any medium, provided the original work is properly cited.

Copyright (C) 2022 Korean Society of Environmental Engineers
Received November 30, 2020 Accepted May 25, 2021

${ }^{\dagger}$ Corresponding author

E-mail: jhbcbe@cbnu.ac.kr

Tel: +82-43-261-2470 Fax: +82-43-264-2465

ORCID: 0000-0002-6662-7848 
requirement of a high reaction temperature, and accumulation of VFAs in the reactor [7]. To solve these limitations, microbial electrolysis cells (MECs) have recently been introduced as a new method for the efficient production of biogas from organic materials [8, 9]. Organic matter in MECs is converted into $\mathrm{CO}_{2}, \mathrm{H}^{+}$, and $\mathrm{e}^{-}$by electrochemically active microorganisms on the anodes. The converted $\mathrm{e}^{-}$moves to the cathode through the power supply and is consumed during the production of $\mathrm{CH}_{4}$ and $\mathrm{H}_{2}$ [10]. Moreover, $\mathrm{H}_{2}$ is combined with $\mathrm{CO}_{2}$ to produce $\mathrm{CH}_{4}$, which results in higher methane production and faster stabilization rates than conventional $\mathrm{AD}$ [9, 11, 12]. MECs can also remove various organic and inorganic pollutants, such as nitrobenzene, sulfate, and nitrate [13], ensuring high organic matter removal efficiency and decomposition rates [14]. According to the results of recent MECs studies, rapid stabilization and high methane yield occur at the beginning of an operation due to electrochemical reactions. However, in the stabilization phase, biological reactions have a greater impact on methane production than electrochemical reactions [12, 15]. For this reason, studies on MECs have been conducted not only on electrochemical reactions (development of high-efficiency low-cost electrodes [16], novel reactor design for practical use [17], electrochemical reaction analysis [18], and calculation of electrochemical efficiency [19]) but also on the effect of MECs on microbial communities [14].

Among them, most studies on microorganisms have analyzed microbial communities that live on the surfaces of anodes to investigate the extracellular electron transport mechanisms between microorganisms and anodes. However, research has shown that methane production in bulk sludge is more important than methane production at the electrode, and there is a need to pay attention to the effect of electrochemical reactions on bulk sludge [20]. For bacterial communities, well-known species, such as Geobacter, Bacteroides, Shewanella, Pseudomonas, and Clostridium, were dominant in both $\mathrm{AD}$ and $\mathrm{ADMEC}$ reactors. For archaeal communities, two groups, which are acetoclastic (e.g., Methanosarcina and Methanosaeta) and $\mathrm{H}_{2}$-dependant methanogens (e.g., Methanosarcina, Methanobacterium, Methanoculleus, Methanobrevibacter, and Methanosphaera), could be divided as the main species for methane-generating archaea in both $\mathrm{AD}$ and $\mathrm{ADMEC}$ reactors [21]. While much progress has been made in previous studies, various, and at times inconsistent and uncertain microbial results have been reported in both $\mathrm{AD}$ and $\mathrm{ADMEC}$ studies [21]. Thus, there is a need to study the microbial communities in bulk solutions that influence $\mathrm{CH}_{4}$ production and elucidate the characteristics of $\mathrm{CH}_{4}$ generation at deep taxonomic levels. Examples of tools for analyzing microbial communities include strain isolation, cloning and sequencing, terminal restriction fragment length polymorphism (T-RFLP), ribosomal intergenic spacer analysis (RISA), fluorescence in situ hybridization (FISH), PCR-denaturing gradient gel electrophoresis, and quantitative PCR (qPCR). However, these tools have various issues, including difficulty of use, long analysis process, high analysis costs, low sensitivity, and low reliability [22]. The development of next-generation sequencing (NGS) techniques (including 454-pyrosequencing and Illumina) has revolutionized the fields of microbial ecosystems and genetics [23]. These techniques provide low-cost qualitative and quantitative data for all types of nucleic acids [24].
A previous study analyzed microbial communities in a bulk solution using 454-pyrosequencing in the bulk sludge of a conventional $\mathrm{AD}$ and an $\mathrm{ADMEC}$ reactor treating food waste leachate. ADMEC was found to enhance the relative abundance of acetoclastic and methylotrophic methanogens [15]. This result shows that supplied voltage influences microbial communities in ADMECs treating food waste and can produce methane more efficiently than conventional $\mathrm{AD}$. However, it is difficult to accurately evaluate the effect of MECs on the enhancement of methylotrophic methanogens in a bulk solution by referring to this result alone. Various process conditions, such as substrates, operational parameters, and inoculums affect microbial communities [25]. In particular, substrate characteristics significantly affect $\mathrm{AD}$ performance and microbial community structures because the reaction rates and pathways of methane production could be affected by the biochemical components of the substrate [21]. Therefore, it is necessary to conduct further research using other substrates and perform an analysis based on metagenomic data.

In this study, the effects of MECs on microbial changes in bulk sludge were investigated in a conventional $\mathrm{AD}$ and an ADMEC using a mixture of primary sludge and waste-activated sludge. The 454-pyrosequencing method was used to analyze the community changes and determine the dominant microbial communities. In addition, by comparing microbial communities with those on various substrates, the influence of MECs on microbial communities in different environments was determined.

\section{Materials and Methods}

\subsection{Reactor Preparation}

To determine the influence of MECs on the $\mathrm{AD}$ of microbial communities, two reactor systems were used: first, a voltage $(0.3 \mathrm{~V})$ was applied from a DC supply using electrodes in a single-chamber ADMEC. Second, a conventional AD reactor, which is a control reactor, was operated under identical conditions to those in the first reactor, but in the absence of electrodes. In both cases, the reactor was made of an acrylic cylinder (diameter: $280 \mathrm{~mm}$, height: $410 \mathrm{~mm}$ ), and the total reactor volume was $25 \mathrm{~L}$ with an effective volume of $15 \mathrm{~L}$. Six sets of anodes and cathodes $(150 \times 300 \mathrm{~mm}$, area: $0.090 \mathrm{~m}^{2}$ ) were used for the bioelectrochemical reactions of the microorganisms. Each electrode was graphite carbon coated with $\mathrm{Ni}$ electrolyte on the whole area of electrodes (anode: 0.54 $\mathrm{m}^{2}$, cathode: $0.54 \mathrm{~m}^{2}$ ) to increase the electrical conductivity [16]. A Ni electrolyte solution was prepared with 0.5 -g polyethylenimine (Thermo Fisher Scientific Inc., NJ, USA) and 0.25-g nickel chloride $\left(\mathrm{NiCl}_{2}\right.$, Sigma-Aldrich Co., MO, USA) with $1 \mathrm{~L}$ of distilled water. Using a direct current (DC) power supply, Ni was simultaneously loaded onto the graphite carbon surface by electrophoretic deposition at $30 \mathrm{~V}$ for $30 \mathrm{~min}$ using a DC power supply (OPA series, ODA Technologies Co. Ltd., Incheon, South Korea). In total, 30.125 $\mathrm{g}$ of $\mathrm{MnSO}_{4} \cdot \mathrm{H}_{2} \mathrm{O}, 19.75 \mathrm{~g}$ of $\mathrm{KMnO}_{4}, 0.5684 \mathrm{~g}$ of ion phthalocyanine (FePc), and $0.5761 \mathrm{~g}$ of copper phthalocyanine (CuPc) were dissolved in $1 \mathrm{~L}$ of distilled water, then stirred for $2 \mathrm{~h}$ to create a composite metal catalyst solution. This solution was heated for $90 \mathrm{~s}$ in a microwave at $400^{\circ} \mathrm{C}$ and then cooled for $60 \mathrm{~s}$ at ambient temperature. 
The same process was repeated five times, and the solution was coated onto graphite carbon cathodes. Only the cathode was coated with $\mathrm{Cu}$ and $\mathrm{Fe}$ to improve the electron transfer rate for $\mathrm{CO}_{2}$ reduction on the cathode surface area and reinforce the durability of the electrode for long-term operation.

After fixing the electrodes using an acrylic frame, they were placed in the reactor, and an agitator (agitation speed of $100 \mathrm{rpm}$ ) was installed at the top of the reactor to ensure complete mixing. To reduce the internal resistance, which is an important operating parameter in MEC reactions, electrode separation was minimized (electrode separation distance: $1 \mathrm{~mm}$ ), and a non-woven cloth (1-mm thick) was placed between the anodes and cathodes to prevent short circuits from direct contact. The generated gas was collected in a Tedlar gas bag (100 L, 0.05 mm thickness, Top Trading Eng, Republic of Korea), after washing the Tedlar bag three times in nitrogen gas (99.999\%). Gas was collected in this bag for one day, after which the bag was replaced before gas collection resumed. The biogas content was analyzed using gas chromatography (GC) (GOW-MAC, Series 580, USA) attached to a thermal conductivity detector. The generated methane gas was converted into a standard state using an ideal gas flow.

A titanium wire (0.1-mm thickness) was used to connect each electrode with a DC power supply (Keithley 2230-30-1 Triple Channel DC Power Supply, USA) in parallel, and 0.3 V was applied (the optimal applied voltage of electrochemical reactions in microbial for methane production) [21] (Fig. S1).

\subsection{Reactor Operation}

The substrate used in this study was a 4:1 ratio mixture of primary sludge and waste-activated sludge from a city sewage treatment plant. The mean total chemical oxygen demand (TCODCr) of the mixed sludge was $45,000 \mathrm{mg} / \mathrm{L}$, and the mean volatile solid (VS) was $25,000 \mathrm{mg} / \mathrm{L}$. More details on the substrate characteristics are described in Table 1 . The seed sludge for the $\mathrm{AD}$ and ADMEC reactors was collected from a full-scale mesophilic $\mathrm{AD}$ reactor in waste-to-energy plants. The characteristics of the seed sludge are listed in Table S1. The organic loading rate (OLR) was $2 \mathrm{~kg}-\mathrm{VS} / \mathrm{m}^{3} / \mathrm{d}$, and the hydraulic retention time of the reactors was $20 \mathrm{~d}$. All reactors were set in a temperature-controlled room at $35^{\circ} \mathrm{C}$ and operated in accordance with a sequencing batch reactor (SBR) that feeds and withdraws once a day.

Table 1. Characteristics of Mixed Sludge (Primary Sludge to Waste Activated Sludge Ratio of 4:1)

\begin{tabular}{lcc}
\hline Characteristic & Range & Mean \\
\hline $\mathrm{pH}$ & $5.7-6.6$ & $6.1 \pm 0.21$ \\
Alkalinity (mg/L as $\left.\mathrm{CaCO}_{3}\right)$ & $2,000-3,900$ & $3,100 \pm 470$ \\
TCODCr (mg/L) & $38,000-54,000$ & $45,000 \pm 3,700$ \\
SCODCr (mg/L) & $6,700-14,000$ & $9,600 \pm 1,600$ \\
TS (mg/L) & $27,000-34,000$ & $30,500 \pm 3,750$ \\
VS (mg/L) & $21,000-29,000$ & $25,000 \pm 2,300$ \\
T-N (mg/L) & $1,500-2,300$ & $2,000 \pm 180$ \\
\hline
\end{tabular}

TCOD, total chemical oxygen demand; SCOD, soluble chemical oxygen demand; TS, total solid; VS, volatile solids; T-N, total nitrogen

\subsection{Pyrosequencing}

\subsubsection{Sampling and DNA extraction}

Bulk solutions of $\mathrm{AD}$ and $\mathrm{ADMEC}$ reactors were sampled after both $\mathrm{AD}$ and $\mathrm{ADMEC}$ reactors reached a steady state (approximately $150 \mathrm{~d}$ after operation). The DNA isolation buffer solution (Zymo Research Inc., Irvine, CA, USA) was injected into each sample, and each sample was stored at $-60^{\circ} \mathrm{C}$. DNA extraction of bulk sludge, the analysis target, was performed according to the manufacturer's instructions using the FastDNA SPIN kit for Soil (MP Biomedical, LLC, Santa Ana, CA, USA).

\subsubsection{PCR amplification and pyrosequencing}

PCR amplification was performed using primers targeting the V1 to $\mathrm{V} 3$ regions of the $16 \mathrm{~S}$ rRNA gene, using the extracted DNA as a template. The primers used for bacteria were V1-27F (5’-CCTATCCCCTGTGTGCCTTGGCAGTC-TCAG-AC-GAGTTTG ATCMTGGCTCAG-3'; the underlining indicates the gene-specific section) and V3-518R (5'-CCATCTCATCCCTGCGTGTCTCCGACTCAG-X-AC-WTTACCGCGGCTGCTGG-3'; $X$ indicates the unique barcode for each subject) [26]. The primers used for archaeal organisms were AV1-21F (5'-CCTATCCCCTGTGTGCCTTGGCAGTCTCAG-AG-TCCGGTTGATCCYGCCGG-3') and AV3-519R (5'-CCATCTCATCCCTGCGTGTCTCCGAC-TCAGX-GA-GGTDTT ACCGCGGCKGCTG-3') [26].

Amplification was performed under the following conditions [26]: initial denaturation at $95^{\circ} \mathrm{C}$ for $5 \mathrm{~min}, 30$ cycles of denaturation at $95^{\circ} \mathrm{C}$ for $30 \mathrm{~s}$ each, primer annealing at $55^{\circ} \mathrm{C}$ for $30 \mathrm{~s}$, extension at $72^{\circ} \mathrm{C}$ for $30 \mathrm{~s}$, and a final elongation step at $72^{\circ} \mathrm{C}$ for $5 \mathrm{~min}$. PCR products were confirmed by $2 \%$ agarose gel electrophoresis and visualized using a Gel Doc system (BioRad, Hercules, CA, USA). The amplified products were purified using a QIAquick PCR Purification Kit (Qiagen, Valencia, CA, USA). Equal concentrations of purified products were pooled together, and short fragments (non-target products) were removed using an AMPure bead kit (Agencourt Bioscience, MA, USA). Quality and product size were assessed on a Bioanalyzer 2100 (Agilent, Palo Alto, CA, USA) using a DNA 7500 chip. Mixed amplicons were used for emulsion PCR and then deposited on Picotiter plates. Sequencing was performed at Chunlab, Inc. (Seoul, Republic of Korea) using the GS Junior Sequencing System (Roche, Branford, CT, USA), following the manufacturer's instructions [27].

\subsubsection{Pyrosequencing data analysis}

Readings from the different samples were sorted using the unique barcodes of each PCR product. The sequences of the barcode, linker, and primers were removed from the original sequencing readings. Any readings containing two or more ambiguous nucleotides, low-quality scores (mean score $<25$ ), or readings shorter than $300 \mathrm{bp}$ were discarded. Potential chimera sequences were detected by the Bellerophon method, which compares the BLASTN search results between the forward half and reverse half sequences [28]. After removing chimera sequences, the taxonomic classification of each reading was assigned using the EzTaxon-e database (http://eztaxon-e.ezbiocloud.net). This database contains 16S rRNA gene sequences of type strains with valid published names and representative species-level phylotypes of either cultured or uncultured entries in the GenBank database. It contains a complete 
hierarchical taxonomic classification from the phylum to species.

\subsubsection{Statistical analysis of microbial species diversity}

Microbial species diversity was analyzed in terms of species richness estimators (i.e., Chao1, abundance-based coverage estimator (ACE), and JackKnife), Good's coverage (an estimator of phylotype proportion in a sample), diversity indices, and rarefaction curves of archaea and bacteria. The CLcommunity program (version 3.45) was used for these statistical analyses based on operational taxonomic units (OTUs) obtained through pyrosequencing data analysis.

\subsubsection{Sequencing access number}

The 454-pyrosequencing data used in this study were registered in the NCBI Sequence Read Archive (SRA; accession number SRP105355).

\subsection{Analysis Methods}

\subsubsection{Water qualities}

The sample was extracted from the top valves of the reactor for component analysis. The TCODCr was measured after the solid-liquid separation using a centrifuge (MF-80, Hanil, Republic of Korea, 3,000 rpm, $5 \mathrm{~min}$ ). Other dissolved components, including soluble chemical oxygen demand (SCODCr), were analyzed after filtering through $1.2 \mu \mathrm{m} \mathrm{GF/C} \mathrm{(GF/CTM,} \mathrm{Whatman,} \mathrm{England).} \mathrm{The}$ CODCr was measured using the standard closed reflux method [29]. To analyze VFAs (lactic acid, acetic acid, propionic acid, and butyric acid) and methanol, liquid chromatography (HPLC, YOUNGLIN SDV50A, Republic of Korea) with a Zorbax SB-Aq (4.6-mm ID $\times 150 \mathrm{~mm}$ ) column was used, with $1 \%$ ACN/99\% $20 \mathrm{mM} \mathrm{NaH} \mathrm{PO}_{4}$ used as the mobile phase. The $\mathrm{pH}$ was measured using a pH meter (Orion 420A+, Thermo Scientific, USA), and other standard parameters (alkalinity, TS, VS, T-N, etc.) were analyzed using standard methods [29].

\subsubsection{Biogas}

For component analysis of the generated gas, a thermal conductivity detector (TCD; Gow Macseries580, GOW-MAC, USA) equipped with a Porapak Q (80/100 mesh) column $(1.83 \mathrm{~m} \times 2 \mathrm{~mm})$ was used. Ultra-pure helium was used as the carrier gas. The fluid velocity was set to $15 \mathrm{~mL} / \mathrm{min}$, and the temperatures of the column, injector, and detector were set to $50^{\circ} \mathrm{C}, 80^{\circ} \mathrm{C}$, and $90^{\circ} \mathrm{C}$, respectively.

2.4.3. Microbial communities and scanning electron microscope The Krona graph (dynamic pie chart) was plotted using the Krona visualization tool [30]. A field emission scanning electron microscope (SEM; Ultra Plus, Zeiss, Germany) was used to observe the surface of the electrode, and an energy-dispersive X-ray spectrometer (EDS; NS7, FEI, USA) was used to assess the elemental composition of the electrode surface.

\section{Results and Discussion}

\subsection{Methane Production Analysis}

More methane was generated in ADMEC and stabilized faster than in $\mathrm{AD}$ (Fig. 1). Methane was generated from the beginning of the operation in the ADMEC and reached a steady state after $100 \mathrm{~d}$ of operation. In $\mathrm{AD}$, methane generation began after $90 \mathrm{~d}$, and a steady state was reached after approximately $120 \mathrm{~d}$.

The methane yields in $\mathrm{AD}$ and $\mathrm{ADMEC}$ reactors were respectively $0.32 \pm 0.02 \mathrm{~m}^{3}-\mathrm{CH}_{4} / \mathrm{kg}_{-}-\mathrm{VS}_{\text {inf. }}$ and $0.05 \pm 0.04 \mathrm{~m}^{3}-\mathrm{CH}_{4} / \mathrm{kg}_{-}-\mathrm{VS}_{\text {inf. }}$ during the startup periods, which were $0-119 \mathrm{~d}$ in $\mathrm{AD}$ and $0-89 \mathrm{~d}$ in ADMEC. The methane yield after $120 \mathrm{~d}$, when both reactors reached a steady state, was $0.19 \pm 0.02 \mathrm{~m}^{3}-\mathrm{CH}_{4} / \mathrm{kg}-\mathrm{VS}_{\text {inf. }}$ for $\mathrm{AD}$, and 0.67

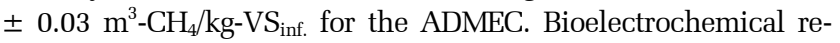
actions might shorten the reactor stabilization period and increase the amount of methane generation and yield in the ADMEC. Furthermore, at a steady state (after 120 d), more VS was removed, and the concentration of total volatile fatty acids (TVFAs) remaining in the reactor was lower in the ADMEC than in the $\mathrm{AD}$ (Table 2). This means that more TVFAs were consumed and converted into methane in the ADMEC, resulting in differences in the amounts of methane generated (Fig. 1). Previous studies have also found that the decomposition rate improves when electrochemically active bacteria on the MEC anode consume VFAs generated during $\mathrm{AD}$ [11]. Moreover, the methane yield was assumed to increase because the $\mathrm{e}^{-}$and $\mathrm{H}^{+}$generated during this process were converted into $\mathrm{H}_{2}$ through electrochemical reactions, and then combined with
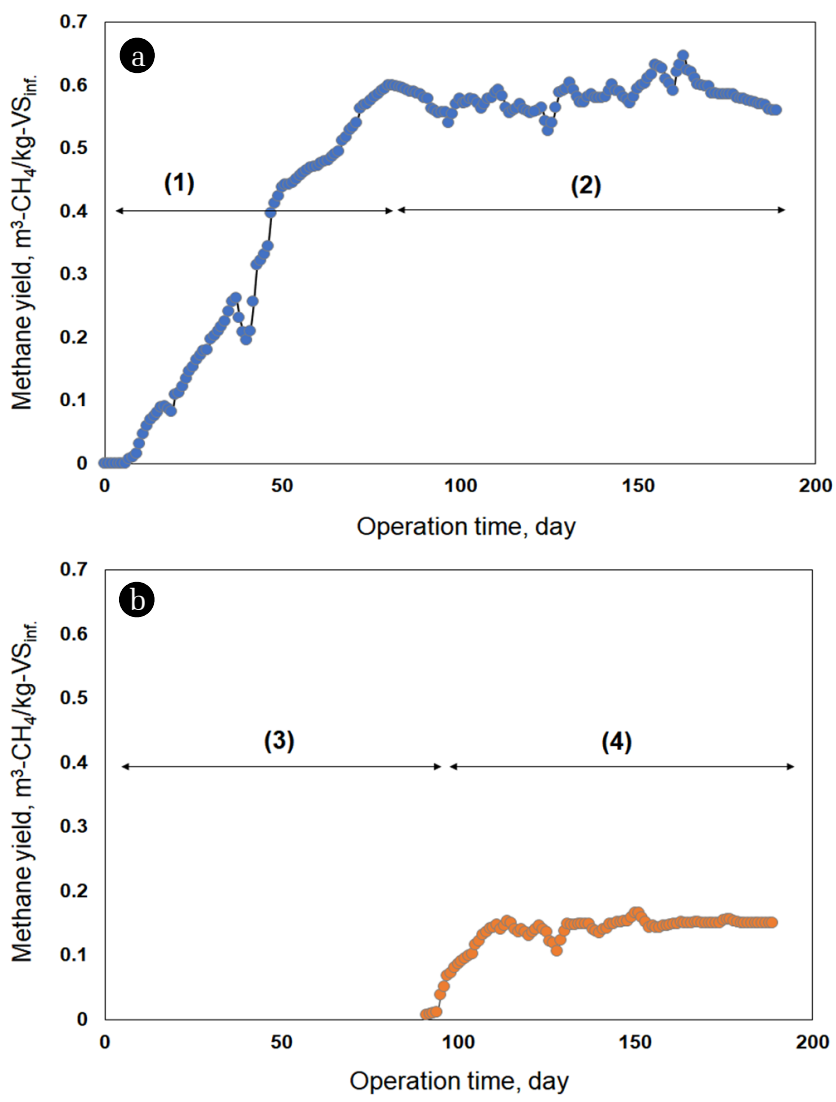

Fig. 1. Profile of methane production. (a): $\operatorname{ADMEC}(\bullet),(b)$ : $\operatorname{AD}(\bullet)$. ADMEC: start-up period (1), and steady-state was reached after approximately $100 \mathrm{~d}(2)$. AD: methane production started after approximately $90 \mathrm{~d}(3)$ and reached steady state after approximately $120 \mathrm{~d}$ (4). AD: anaerobic digester. ADMEC: anaerobic digester combined with microbial electrolysis cells. 
Table 2. VS Reduction and TVFAs Concentration in the Reactors during the Steady State Period

\begin{tabular}{|c|c|c|c|c|c|c|c|c|}
\hline State & \multicolumn{4}{|c|}{ VS reduction $(\mathrm{mg} / \mathrm{L})$} & \multicolumn{4}{|c|}{ TVFAs (mg/L) } \\
\hline \multirow{3}{*}{$\begin{array}{l}\text { Steady } \\
\text { state }\end{array}$} & \multicolumn{2}{|c|}{ AD } & \multicolumn{2}{|c|}{ ADMEC } & \multicolumn{2}{|c|}{ AD } & \multicolumn{2}{|c|}{ ADMEC } \\
\hline & Range & Mean & Range & Mean & Range & Mean & Range & Average \\
\hline & $4,820-9,420$ & $7,677 \pm 883$ & $8,900-10,800$ & $9,835 \pm 648$ & $1,858-2,705$ & $2,269 \pm 275$ & $1,993-2,664$ & $2,210 \pm 204$ \\
\hline
\end{tabular}

AD: anaerobic digesters; ADMEC anaerobic digester combined with microbial electrolysis cells; TVFAs: total volatile fatty acids; VS: volatile solid

$\mathrm{CO}_{2}$ to produce $\mathrm{CH}_{4}$ [31]. If $\mathrm{H}_{2}$ and $\mathrm{CO}_{2}$ react to produce additional methane; the gas composition between $\mathrm{AD}$ and $\mathrm{ADMEC}$ should be different. However, according to the results of our previous studies, during the startup period, the hydrogen content in ADMEC was higher than that in $\mathrm{AD}$. Conversely, during the steady-state period, the gas compositions in the two reactors were similar, and the microbial communities between $\mathrm{AD}$ and $\mathrm{ADMEC}$ were different [15]. Based on these results, it was suggested that the increase in methane yield and production in the ADMEC was due to changes in microbial communities rather than bioelectrochemical reactions.

In this study, using mixed sludge as the substrate, a difference was observed in the gas composition between the $\mathrm{AD}$ and $\mathrm{ADMEC}$ during the startup period (Fig. 2), but it was negligible during the steady-state period. The $\mathrm{pH}$ ranges during the startup and steady-state periods were 7.4-8.0 and 7.5-7.7, respectively, in $\mathrm{AD}$ and 7.5-8.0 and 7.5-7.8, respectively, in ADMEC. This means that

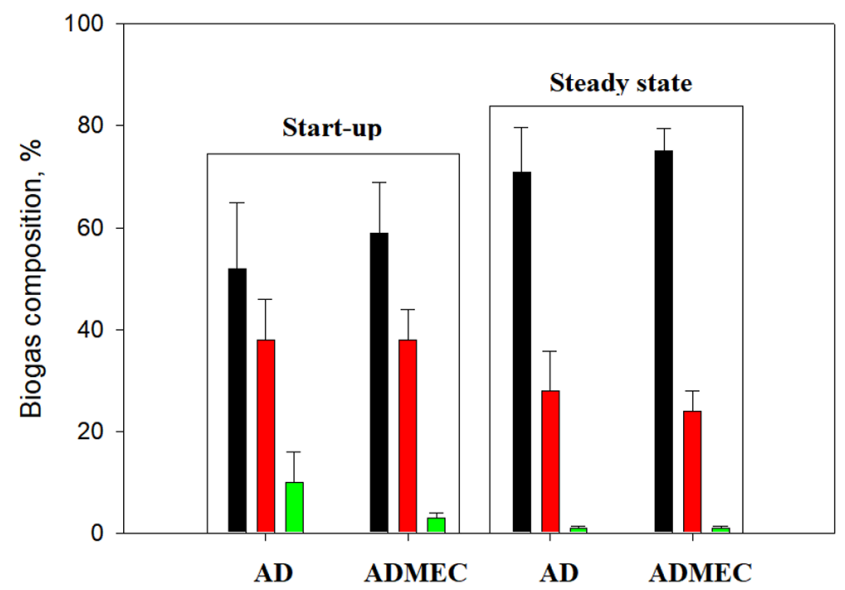

Fig. 2. Gas composition during the start-up period (AD; ADMEC) and the steady-state period (AD; ADMEC, also see Fig. 1). $\mathbf{0}: \mathrm{CH}_{4}$, ㅁ: $\mathrm{CO}_{2}, \square: \mathrm{H}_{2}, \mathrm{AD}$ : anaerobic digester, and ADMEC: anaerobic digester combined with microbial electrolysis cells. higher methane yield in ADMEC is not an effect of the operating $\mathrm{pH}$ conditions, but instead reflects increased microbial activity with electrochemical help during the steady-state period.

\subsection{Microbial Species Diversity}

To investigate the effects of MECs on microbial activation, a species diversity analysis was performed on the bulk sludge of ADMEC and $\mathrm{AD}$ under steady-state conditions. In the rarefaction curve results ( $3 \%$ cutoff), the operating taxonomic units (OTUs), which are indices that show individual organisms or organism communities, showed that there were fewer archaeal communities in ADMEC than in $\mathrm{AD}$. Moreover, although bacterial communities failed to reach saturation, there were fewer bacterial communities in ADMEC than in $\mathrm{AD}$ (Fig. S2). The CLcommunity program (version 3.45) was used to evaluate the diversity of archaea and bacterial communities from various aspects by obtaining the ACE, Chao1, JackKnife, and Shannon diversity indices (Table 3). The coverage values of the pyrosequencing libraries were over 90\% (Goods Lib. coverage index). The species diversity indices of archaea and bacteria were higher in $\mathrm{AD}$ than in ADMEC, similar to the results of rarefaction curve analysis. This means that the microbial communities in $\mathrm{AD}$ were more diverse than those in ADMEC. Previous studies using food waste leachate as a substrate also showed that $\mathrm{AD}$ has greater species diversity than ADMEC [15]. Here, high species diversity increases the ecological stability because a wider range of microbial groups implies a greater potential for rapid adaptation to environmental changes [32]. This study found that the species diversity of archaeal and bacterial communities decreased in ADMEC, regardless of the substrate used. Considering the relationship between species diversity results and the methane production shown in Fig. 1, several microbial species were unable to adapt electrochemically in ADMEC, leading to a possible reduction in ecological stability; however, the microbial species that adapt are believed to have a more positive effect on methane production than species that do not adapt.

\subsection{Archaea Community Analysis}

The differences between the microbial communities in the two

Table 3. Microorganism Community Species Diversity Indices for AD and ADMEC [30-34]

\begin{tabular}{|c|c|c|c|c|c|c|}
\hline \multirow{2}{*}{ Samples } & \multicolumn{4}{|c|}{ OTU richness } & \multirow{2}{*}{$\begin{array}{l}\text { OTU diversity } \\
\text { Shannon [33] }\end{array}$} & \multirow{2}{*}{$\begin{array}{l}\text { Goods Lib. } \\
\text { Coverage [34] }\end{array}$} \\
\hline & No. of OTUs & ACE [30] & Chao1 [31] & JackKnife [32] & & \\
\hline $\mathrm{AD}$-archaea & 6,227 & 81.1 & 66.2 & 65.5 & 2.4 & 0.99 \\
\hline ADMEC-archaea & 5,853 & 34.7 & 34.0 & 34.0 & 1.5 & 0.99 \\
\hline AD-bacteria & 14,913 & $1,356.3$ & $1,145.4$ & $1,627.7$ & 4.1 & 0.98 \\
\hline ADMEC-bacteria & 8,023 & $1,122.2$ & 834.2 & 995.0 & 3.8 & 0.97 \\
\hline
\end{tabular}

OTUs were calculated using Mothur $(p>0.97)$

AD: anaerobic digesters; ADMEC: anaerobic digester combined with microbial electrolysis cells; ACE: abundance-based coverage estimator 
reactors were determined using 454-pyrosequencing. This study used the Krona tool, a recently developed method that expands and visualizes radial space-filling (RSF) displays, to visualize microbial communities in more detail than existing methods [30]. First, the taxonomic differences in archaeal communities that influenced the methane production in the bulk sludge of $\mathrm{AD}$ and ADMEC were determined [38] (Fig. 3). Increasing the distance from the center of the circle indicates a higher level of taxonomic classification.

Based on the taxonomic results, there were clear differences between the microorganisms of the archaeal communities in the bulk solution of $\mathrm{AD}$ and $\mathrm{ADMEC}$. The dominant species in the $\mathrm{AD}$ bulk solution was Methanobacterium beijingense, accounting for $63 \%$ of the entire population, followed by Methanosaeta concilii, accounting for $20 \%$ (Fig. 3(a)). In the ADMEC bulk solution, Methanoculleus bourgensis was the dominant species, accounting for $69 \%$ of the entire population, and unclassified microbial EU662692 s represented 25\% of the entire population. As shown in Fig. 3(b), EU662692_s is a part of the Thermoplasmata class with respect to taxonomy. According to previous studies, the Methanoculleus bourgensis and Thermoplasmata classes, which were dominant in the ADMEC of this study, live on the anode surface of bioelectrochemical systems [39]. Methanobacterium beijingense, which represents a high proportion of the microbial community in $\mathrm{AD}$, is a hydrogenotrophic methanogen that generates methane from $\mathrm{H}_{2}, \mathrm{CO}_{2}$, and formate, and does not use substrates of methanol, ethanol, trimethylamine, isobutanol, or isopropanol. The optimal growth temperature and $\mathrm{pH}$ of this microorganism are $37^{\circ} \mathrm{C}$ and $7.2-7.7$, respectively [40]. Methanosaeta concilii, which constitutes the next highest proportion, is an acetoclastic methanogen that generates methane from acetic acid, and its optimal growth temperature and $\mathrm{pH}$ are $35^{\circ} \mathrm{C}$ and $7.1-7.5$, respectively. If methanol, trimethylamine, formic acid, propionic acid, butyric acid, and pyruvic acid come into contact with this microorganism, growth and methane production cease [41]. In short, the main microorganisms of $\mathrm{AD}$, Methanobacterium beijingense, and Methanosaeta concilii, use their respective substrates (acetic acid and formate) to produce methane. The presence of other compounds had a negative effect on methane production.

Methanoculleus bourgensis was the dominant species in the ADMEC. It generates methane using $\mathrm{CO}_{2}, \mathrm{H}_{2}$, formate, 2-propanol, 2-butanol, and other secondary alcohols [42], with simultaneous acetoclastic and hydrogenotrophic methanogenesis [43]. The optimal growth temperature and $\mathrm{pH}$ were $37^{\circ} \mathrm{C}$ and 6.7 [44], respectively. EU662692 s, which had the next highest abundance in the ADMEC, is an unclassified microorganism; thus, the characteristics of the Thermoplasmata class were analyzed. Thermoplasmata is a methylotrophic methanogen that generates methane using methylamines and methanol as energy and carbon sources. Until recently, only two species participating in methylotrophic methanogens were discovered to be Thermoplasmata and Methanosarcinaceae [45]. Methylotrophic methanogenesis plays an important role in methane production by consuming methanol and methylated amines, which are noncompetitive substrates [46]. According to Florencio et al. [47], methylotrophic methanogens have higher methane productivity than acetoclastic or hydrogenotrophic methanogens, and methanol, which is an intermediate product of the methane production pathway, is an important substrate in terms of methane production. The Gibbs free energy for methanol production from $\mathrm{CO}_{2}(-314.6 \mathrm{~kJ} /$ reaction $)$ is lower than that for the etoclastic $(-31$ $\mathrm{kJ} /$ reaction) and hydrogenotrophic $(-131 \mathrm{~kJ} /$ reaction $)$ methanogenesis reactions. ADMEC bioelectrochemically accelerates the methanol pathway and the production rate, and then the methanol produced on the cathode is directly converted to methane by improved methylotrophic methanogens [48].

To summarize the archaeal community changes in $\mathrm{AD}$ and ADMEC, microbial communities that generate methane from certain substrates (formate and acetate) were found in $\mathrm{AD}$, while Methanoculleus bourgensis, which generates methane using various substrates (formate, 2-propanol, 2-butanol, etc.), and the
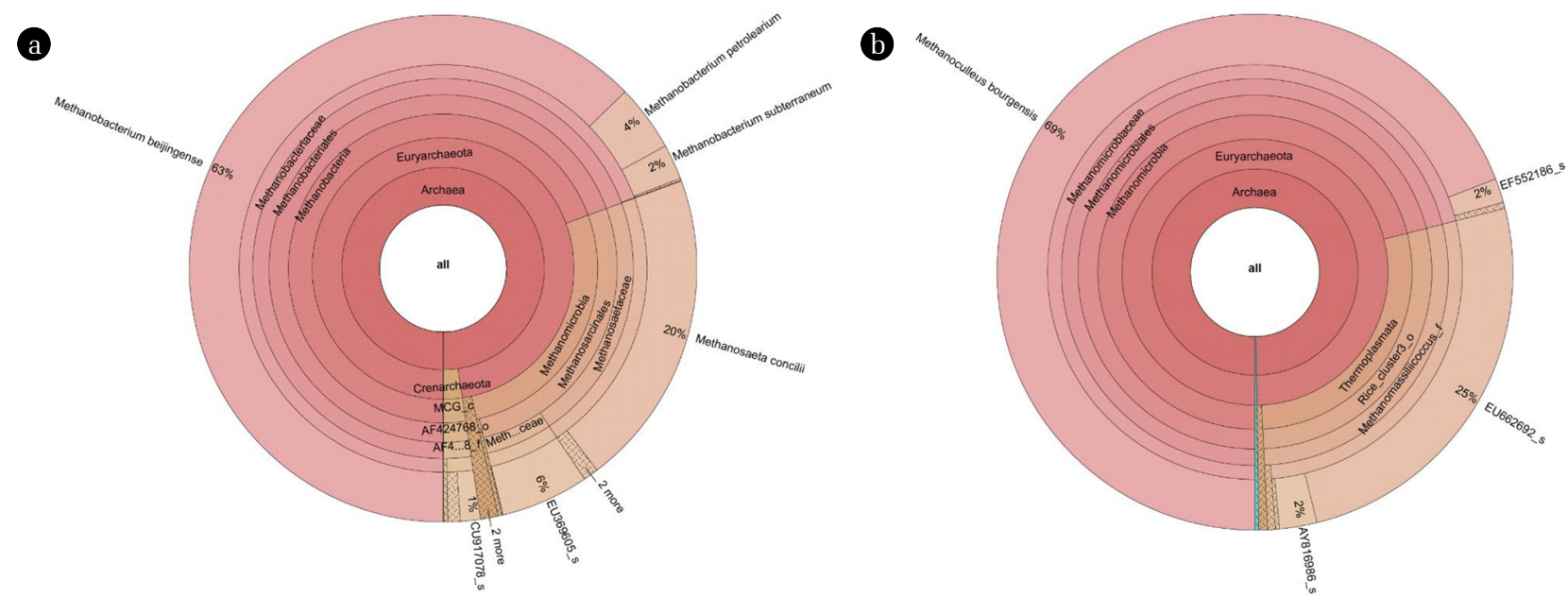

Fig. 3. Krona visualization method expressing archaea communities in (a) AD (anaerobic digester) and (b) ADMEC (anaerobic digester combined with microbial electrolysis cells) through 454-pyrosequencing analysis. Increasing distance from the center signifies increasingly lower taxonomic nodes. The dominant species in AD was Methanobacterium beijingense, and the dominant species in ADMEC was Methanoculleus bourgensis (Table S2). 
Thermoplasmata community, which is a methylotrophic methanogen that generates more methane than other methanogens (such as acetoclastic or hydrogenotrophic methanogens), were dominant in the ADMEC. When combined with species diversity results, the diversity and population of archaea communities in ADMEC were lower than those in $\mathrm{AD}$. This microbial community change resulted in a difference in methane production, as shown in Fig. 1. Moreover, in a microbial community analysis of ADMEC using food waste leachate [15], Methanosarcina thermophila, which grows using acetate, methanol, methylated amines, etc., and is part of the Methanosarcinaceae family, increased substantially in abundance [49].

These results demonstrate that this environment facilitates the growth of methylotrophic methanogens in ADMECs (Table 4). The cathode used in this study was coated with a Cu-supported transition metal, which is known to be a catalyst for methane production (Fig. S3). The SEM and EDS results showed that Fe and Ni were the main coated materials of the cathode surface with a composition of $27 \%$, and the $\mathrm{Cu}$ composition on the cathode surface was approximately $7.0 \%$. According to the results of density functional theory (DFT) calculations in a previous study [50], Cu-supported transition metals are catalysts advantageous for methanol production. In other words, the Cu-supported transition metal catalyst causes the production of methanol with low activation energy, as opposed to a reaction in which methane is produced directly through electrochemical reactions, and the methanol produced during this process provides an environment that facilitates the growth of methylotrophic methanogens. In this study, the methanol concentration in the ADMEC bulk solution was 3.4 times higher than that in the $\mathrm{AD}$ bulk solution, and the methanol concentration in the bulk solution of $\mathrm{ADMEC}$ and $\mathrm{AD}$ during the operation periods was 2,183 $\pm 667 \mathrm{mg} / \mathrm{L}$ and $637 \pm 85 \mathrm{mg} / \mathrm{L}$, respectively (Fig. S4). This result indicates that the $\mathrm{Cu}$-coated cathode in ADMEC contributed to methanol production from $\mathrm{CO}_{2}$ and electrons, which provided highly concentrated methanol conditions in the bulk solution of ADMEC. The produced methanol provided a favorable environment for enriching methylotrophic methanogens, which could use methanol as a source of methane. In summary, when Cu-supported transition metal catalysts are used as electrodes in ADMECs, they may electrochemically produce methanol. Methanol was used to activate methylotrophic methanogens, resulting in a higher methane yield than that from $\mathrm{AD}$.

\subsection{Bacterial Community Analysis}

The influence of electrochemical reactions on the bacterial communities in $\mathrm{AD}$ and ADMEC was also analyzed. FJ826495_s was the dominant species in $\mathrm{AD}$, accounting for $44 \%$ of all bacterial abundance, followed by GQ138794_s (9\%), as shown in Fig. 4. These microorganisms were taxonomically categorized into Clostridia and Erysipelotrichi classes. GQ138794_s, which accounted for only $9 \%$ of $\mathrm{AD}$, was found to be the dominant species in the ADMEC, representing 30\%, followed by Cloacamonas_f_uc, which accounted for $21 \%$. These microorganisms were unclassified; thus, their lowest known taxonomic levels were analyzed. The results showed that GQ138794_s is part of the Erysipelotrichi class, and Cloacamonas $f_{-} u c$ belongs to the phylum Cloacamonas. Clostridia are one of the main bacteria commonly found in moderate-temperature $\mathrm{AD}$. Clostridia contributes to hydrolysis, acidogenesis, and syntrophic acetate oxidation (SAO) during digestion [51]. The Erysipelotrichi class is involved in the hydrolysis stage of $\mathrm{AD}$ [52] and inhabits microbial fuel cells [53].

There are few environmental studies regarding these microorganisms, and most are related to metabolic disorders in humans and animals [54]. For example, in an experiment conducted by Stolze et al. [55] on rats, the Erysipelotrichi class was observed to have an abundance of three and seven times higher in the guts of rats fed Western and high-fat diets, respectively, than rats fed a standard chow diet [55]. The Erysipelotrichi class is more active in the gut of obese animals [56]. The mixed sludge used as the substrate in this study contained a significant amount of non-biodegradable organic matter from cell debris through cell death and the accumulation of non-biodegradable substances [57]; thus, hydrolysis was limited [54]. As non-biodegradable organic matter was also decomposed in the MECs [59], there was an increase in the amount of substrate that could be used by microorganisms in the ADMEC, leading to the formation of an advantageous environment for the habitation of Erysipelotrichi.

The species with the second highest abundance in ADMEC were categorized as belonging to the phylum Cloacamonas. This microorganism obtains energy from amino acids, sugars, and carboxylic acid fermentation via the Embden-Meyerhof pathway. It has five dominant types of ferredoxin oxidoreductases that participate in the amino acid fermentation process [60]. Moreover, the Cloacamonas phylum can produce fatty acids while fermenting highly enriched hydrolysis products [61]. Its members are classified

Table 4. Substrates for Methane Production Analysis and Dominant Archaea Community in AD and ADMEC Using Mixed Sludge (primary sludge to waste sludge ratio $=4: 1$ ) and Food Waste Leachate

\begin{tabular}{|c|c|c|c|c|}
\hline Substrate & Reactor type & Microbe & Substrates for methane production & Reference \\
\hline \multirow{2}{*}{$\begin{array}{l}\text { Mixed } \\
\text { Sludge }\end{array}$} & $\mathrm{AD}$ & $\begin{array}{l}\text { Methanobacterium beijingense } \\
\text { Methanosaeta concilii }\end{array}$ & $\begin{array}{c}\mathrm{H}_{2}, \mathrm{CO}_{2} \text {, formate } \\
\mathrm{H}_{2}, \mathrm{CO}_{2}, \text { acetate }\end{array}$ & This study \\
\hline & ADMEC & $\begin{array}{l}\text { Methanoculleus bourgensis } \\
\text { Thermoplasmata }\end{array}$ & $\begin{array}{c}\mathrm{CO}_{2}, \mathrm{H}_{2} \text {, formate, 2-propanol, 2-butanol } \\
\text { Methylamines, methanol }\end{array}$ & This study \\
\hline \multirow{2}{*}{$\begin{array}{l}\text { Food waste } \\
\text { Leachate }\end{array}$} & $\mathrm{AD}$ & $\begin{array}{l}\text { Methanobacterium beijingense } \\
\text { Methanobacterium petrolearium }\end{array}$ & $\begin{array}{l}\mathrm{H}_{2}, \mathrm{CO}_{2} \text {, formate } \\
\mathrm{H}_{2}, \mathrm{CO}_{2} \text {, formate }\end{array}$ & {$[13]$} \\
\hline & ADMEC & $\begin{array}{l}\text { Methanosarcina thermophila } \\
\text { Methanobacterium formicicum }\end{array}$ & $\begin{array}{l}\mathrm{H}_{2} \text {, } \mathrm{CO}_{2} \text {, acetate, methanol, methylated amines } \\
\qquad \mathrm{H}_{2}, \mathrm{CO}_{2} \text {, formate }\end{array}$ & {$[13]$} \\
\hline
\end{tabular}

AD: anaerobic digesters; ADMEC: anaerobic digester combined with microbial electrolysis cell 

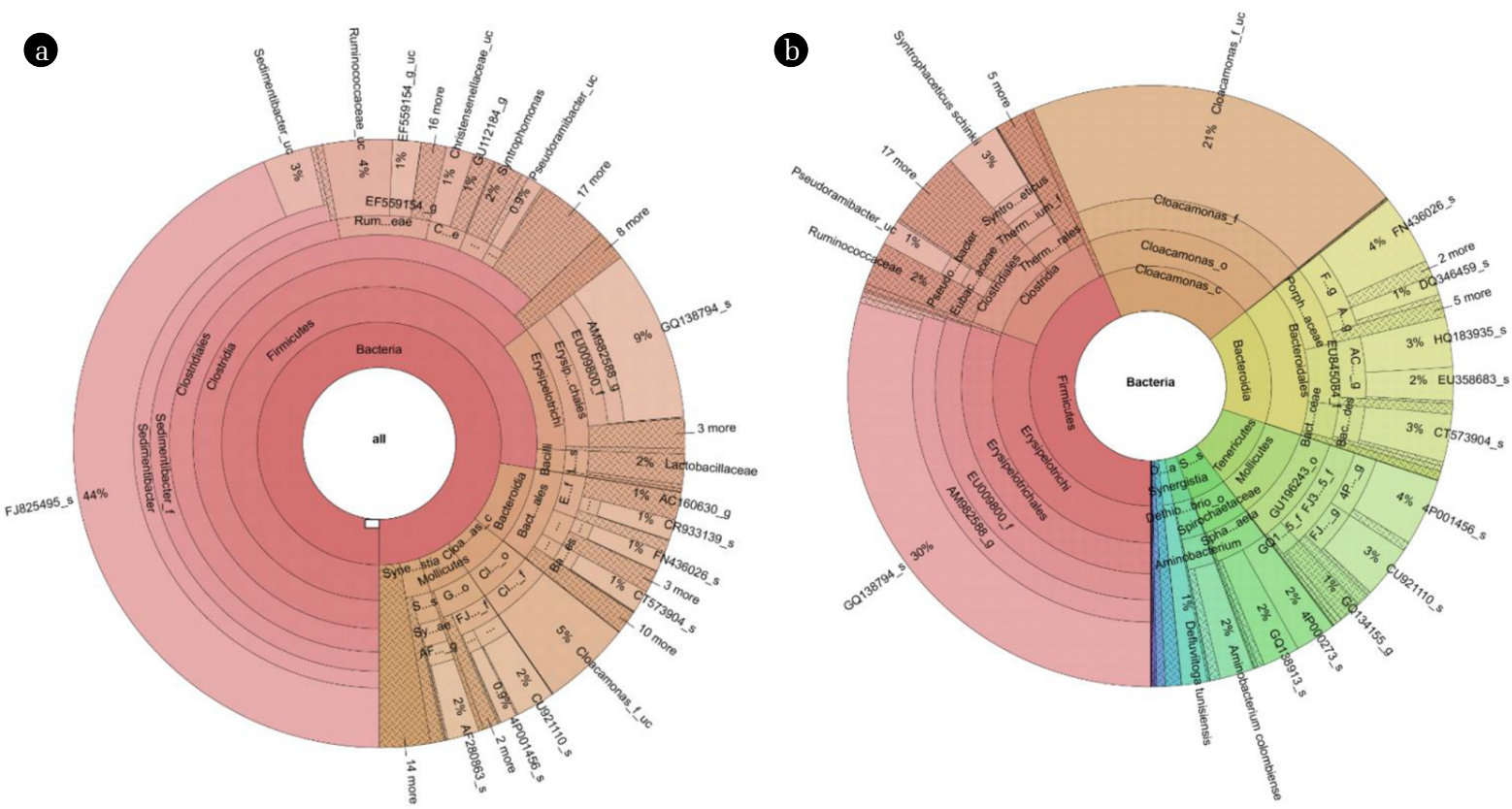

Fig. 4. Krona visualization method expressing bacterial communities in (a) AD (anaerobic digester) and (b) ADMEC (anaerobic digester combined with microbial electrolysis cells) through 454-pyrosequencing analysis. FJ825495_s (Clostridia class) in AD, and GQ138794_s (Erysipelotrichi class) in ADMEC (Table S3).

as syntrophic bacteria that can convert $\mathrm{C}_{n} \mathrm{H}_{2 \mathrm{n}+1} \mathrm{OH}$ and fatty acids into acetate, $\mathrm{H}_{2}$, and $\mathrm{CO}_{2}$ [29]. In ADMEC, there was a larger decrease in the Clostridia class, which serves a similar role as the Cloacamonas phylum, compared to $\mathrm{AD}$, and it is difficult to directly compare the activity of the two microbial communities. However, ADMEC showed a greater increase in the Erysipelotrichi class, which is found in environments with high organic matter concentration, and the Cloacamonas phylum, which takes part in various amino acid fermentation processes, as compared with $\mathrm{AD}$. This implies that the methane production rate increases with highly biodegradable organic matter, which might be generated by both Erysipelotrichi classes.

\section{Conclusions}

The results of this study confirm that faster organic matter decomposition and higher methane yield can be achieved in an ADMEC compared to $\mathrm{AD}$. The Cu-coated cathode improves $\mathrm{CO}_{2}$ conversion to methanol and provides environments for enriching methylotrophic methanogens and organic-decomposing microorganisms in bulk solution. Bacterial community analysis showed that biodegradable organic matter that could be used by microorganisms increased in ADMECs compared to $\mathrm{AD}$. The process performance also increased because of the increase in various amino acid fermentation microorganisms. From the archaeal community, microorganisms that produce methane from certain substrates were dominant in $\mathrm{AD}$, but microorganisms using noncompetitive substrate methanol, which was produced electrochemically through a $\mathrm{Cu}$-supported transition metal catalyst, were dominant in ADMEC. In addition, this study supports that methylotrophic methanogen, which is a beneficial microorganism group for methane production, is increased in ADMEC regardless of the substrate. These results show that the electrochemical reaction conditions are favorable for the growth of methylotrophic methanogen groups.

\section{Acknowledgments}

This research was supported by the Korea Ministry of Environment as Waste to Energy-Recycling Human Resource Development Project (YL-WE-19-001).

\section{Author Contributions}

J.G.P. (Ph.D.) wrote the original draft and finalized the manuscript. B.L. (Ph.D.) conducted sample analysis and revised the manuscript. U.J.L. (M.S. student) conducted experiments under Park's supervision. H.B.J. (Ph.D. Professor) reviewed and revised the manuscript.

\section{References}

1. Chynoweth DP, Owens JM, Legrand R. Renewable methane from anaerobic digestion of biomass. Renew. Energy 2001;22:1-8.

2. Vavilin VA, Fernandez B, Palatsi J, Flotats X. Hydrolysis kinetics in anaerobic degradation of particulate organic material: an overview. Waste Manag. 2008;28:939-951.

3. Bengtsson S, Hallquist J, Werker A, Welander T. Acidogenic fermentation of industrial wastewaters: effects of chemostat 
retention time and $\mathrm{pH}$ on volatile fatty acids production. Biochem. Eng. J. 2008;40:492-499.

4. Eddy MA, Burton FL, Tchobanglous G, Tsuchihashi R. Wastewater engineering: treatment and resource recovery. New York: McGraw-Hill Education. p. 2048.

5. Chynoweth DP. Environmental impact of biomethanogenesis. Environ. Monit. Assess. 1996;42:3-18.

6. Guo X, Liu J, Xiao B. Bioelectrochemical enhancement of hydrogen and methane production from the anaerobic digestion of sewage sludge in single-chamber membrane-free microbial electrolysis cells. Int. J. Hydrogen Energy 2013;38:1342-1347.

7. Ahring BK, Sandberg M, Angelidaki I. Volatile fatty acids as indicators of process imbalance in anaerobic digesters. Appl. Microbiol. Biotechnol. 1995;43:559-565.

8. Sun R, Zhou A, Jia J, Liang Q, Liu Q, Xing D, Ren N. Characterization of methane production and microbial community shifts during waste activated sludge degradation in microbial electrolysis cells. Bioresour. Technol. 2015;175:68-74.

9. Karthic A, Pandit S, Khilari S, Mathuriya AS, Jung SP. Microbial Electrosynthesis for Harnessing Value-Added Product via Carbon Dioxide Sequestering. In: $12^{\text {th }}$ ed. Bioelectrochemical Systems. Vol. 1 Principles and Process. Springer; 2020. p. 277-298.

10. Wagner RC, Regan JM, Oh SE, Zuo Y, Logan BE. Hydrogen and methane production from swine wastewater using microbial electrolysis cells. Water Res. 2009;43:1480-1488.

11. Villano M, Scardala S, Aulenta F, Majone M. Carbon and nitrogen removal and enhanced methane production in a microbial electrolysis cell. Bioresour. Technol. 2013;130:366-371.

12. Park J, Lee B, Tian D, Jun H. Bioelectrochemical enhancement of methane production from highly concentrated food waste in a combined anaerobic digester and microbial electrolysis cell. Bioresour. Technol. 2018;247:226-233.

13. Coma M, Puig S, Pous N, Balaguer MD, Colprim J. Biocatalysed sulphate removal in a BES cathode. Bioresour. Technol. 2013;130:218-223.

14. Zhang Y, Angelidaki I. Microbial electrolysis cells turning to be versatile technology: recent advances and future challenges. Water Res. 2014;56:11-25.

15. Lee B, Park JG, Shin WB, Tian DJ, Jun HB. Microbial communities change in an anaerobic digestion after application of microbial electrolysis cells. Bioresour. Technol. 2017;234:273-280.

16. Song YC, Kim DS, Woo JH. Effect of epoxy mixed with Nafion solution as an anode binder on the performance of microbial fuel cell. J. Korean Soc. Environ. Eng. 2014;36:1-6.

17. Park JG, Lee B, Shi P, Kim Y, Jun HB. Effects of electrode distance and mixing velocity on current density and methane production in an anaerobic digester equipped with a microbial methanogenesis cell. Int. J. Hydrogen Energy 2017;42:2773227740 .

18. Choi KS, Kondaveeti S, Min B. Bioelectrochemical methane $\left(\mathrm{CH}_{4}\right)$ production in anaerobic digestion at different supplemental voltages. Bioresour. Technol. 2017;245:826-832.

19. Gajaraj S, Huang Y, Zheng P, Hu Z. Methane production improvement and associated methanogenic assemblages in bioelectrochemically assisted anaerobic digestion. Biochem. Eng. J. 2017;117:105-112.
20. Feng Y, Zhang Y, Chen S, Quan X. Enhanced production of methane from waste activated sludge by the combination of high-solid anaerobic digestion and microbial electrolysis cell with iron-graphite electrode. Chem. Eng. J. 2015;259:787-794.

21. Park JG, Jiang D, Lee B, Jun HB. Towards the practical application of bioelectrochemical anaerobic digestion (BEAD): Insights into electrode materials, reactor configurations, and process designs. Water Res. 2020;184:116214.

22. Nam YD, Yi SH, Lim SI. Bacterial diversity of cheonggukjang, a traditional Korean fermented food, analyzed by barcoded pyrosequencing. Food Control 2012;28:135-142.

23. Kim DH, Jang S, Yun YM, et al. Effect of acid-pretreatment on hydrogen fermentation of food waste: microbial community analysis by next generation sequencing. Int. J. Hydrogen Energy 2014;39:16302-16309.

24. Pettersson E, Lundeberg J, Ahmadian A. Generations of sequencing technologies. Genomics 2009;93:105-111.

25. Pawar AA, Karthic A, Lee S, Pandit S, Jung SP. Microbial electrolysis cells for electromethanogenesis: Materials, configurations and operations. Env. Eng. Res. 2022;27(1):200484.

26. Hur M, Kim Y, Song HR, Kim JM, Choi YI, Yi H. Effect of genetically modified poplars on soil microbial communities during the phytoremediation of waste mine tailings. Appl. Environ. Microbiol. 2011;77:7611-7619.

27. Lee J, Kim JR, Jeong S, Cho J, Kim JY. Long-term performance of anaerobic digestion for crop residues containing heavy metals and response of microbial communities. Waste management 2017;59:498-507.

28. Huber T, Faulkner G, Hugenholtz P. Bellerophon: a program to detect chimeric sequences in multiple sequence alignments. Bioinform 2004;20:2317-2319.

29. Park J, Lee B, Shi P, Kwon H, Jeong SM, Jun H. Methanol metabolism and archaeal community changes in a bioelectrochemical anaerobic digestion sequencing batch reactor with copper-coated graphite cathode. Bioresour. Technol. 2018;259:398-406.

30. Ondov BD, Bergman NH, Phillippy AM. Interactive metagenomic visualization in a Web browser. BMC Bioinform. 2011;12:385.

31. Villano M, Aulenta F, Ciucci C, Ferri T, Giuliano A, Majone M. Bioelectrochemical reduction of $\mathrm{CO}_{2}$ to $\mathrm{CH}_{4}$ via direct and indirect extracellular electron transfer by a hydrogenophilic methanogenic culture. Bioresour. Technol. 2010;101:3085-3090.

32. Tilman D, Reich PB, Knops JM. Biodiversity and ecosystem stability in a decade-long grassland experiment. Nature 2006;441:629-632.

33. Chao A, Lee SM. Estimating the number of classes via sample coverage. J. Am. Stat. Assoc. 1992;87:210-217.

34. Chao A. Nonparametric estimation of the number of classes in a population. Scand. J. Stat. 1984;11:265-270.

35. Burnham KP, Overton WS. Robust estimation of population size when capture probabilities vary among animals. Ecology 1979;60:927-936.

36. Spellerberg IF, Fedor PJ. A tribute to Claude Shannon (19162001) and a plea for more rigorous use of species richness, species diversity and the 'Shannon-Wiener'Index. Glob. Ecol. Biogeogr. 2003;12:177-179. 
37. Good IJ. The population frequencies of species and the estimation of population parameters. Biometrika 1953;40:237-264.

38. Feng Y, Zhang Y, Chen S, Quan X. Enhanced production of methane from waste activated sludge by the combination of high-solid anaerobic digestion and microbial electrolysis cell with iron-graphite electrode. Chem. Eng. J. 2015;259:787-794.

39. Bo T, Zhu X, Zhang L, et al. A new upgraded biogas production process: coupling microbial electrolysis cell and anaerobic digestion in single-chamber, barrel-shape stainless steel reactor. Electrochem. Commun. 2014;45:67-70.

40. Ma K, Liu X, Dong X. Methanobacterium beijingense sp. nov., a novel methanogen isolated from anaerobic digesters. Int. J. Syst. Evol. Microbiol. 2005;55:325-329.

41. Patel GB, Sprott GD. Methanosaeta concilii gen. nov., sp. Nov. ("Methanothrix concilii") and Methanosaeta thermoacetophila nom. rev., comb. nov. Int. J. Syst. Evol. Microbio.l 1990;40:79-82.

42. Asakawa S, Nagaoka K. Methanoculleus bourgensis, Methanoculleus olentangyi and Methanoculleus oldenburgensis are subjective synonyms. Int. J. Syst. Evol. Microbiol. 2003;53: 1551-1552.

43. Town JR, Dumonceaux TJ. Laboratory-scale bioaugmentation relieves acetate accumulation and stimulates methane production in stalled anaerobic digesters. Appl. Microbiol. Biotechnol. 2016;100:1009-1017.

44. Ollivier BM, Ma, RA, Garcia JL, Boone DR. Isolation and characterization of Methanogenium bourgense sp. nov. Int. J. Syst. Evol. Microbiol. 1986;36:297-301.

45. Poulsen M, Schwab C, Jensen BB, et al. Methylotrophic methanogenic Thermoplasmata implicated in reduced methane emissions from bovine rumen. Nat. Commun. 2013;4:1428.

46. Summons RE, Franzmann PD, Nichols PD. Carbon isotopic fractionation associated with methylotrophic methanogenesis. Org. Geochem. 1998;28:465-475.

47. Florencio L, Field JA, Lettinga G. Importance of cobalt for individual trophic groups in an anaerobic methanol-degrading consortium. Appl. Environ. Microbiol. 1994;60:227-234.

48. Kleerebezem R., Stams AJ. Kinetics of syntrophic cultures: a theoretical treatise on butyrate fermentation. Biotechnol. Bioeng. 2000;67(5):529-543.

49. Zinder SH, Sowers KR, Ferry JG. Methanosarcina thermophila sp. nov., a thermophilic, acetotrophic, methane-producing bacterium. Int. J. Syst. Evol. Microbiol. 1985;35:522-523.
50. Qiu M, Tao H, Li R, et al. Insight into the mechanism for the methanol synthesis via the hydrogenation of $\mathrm{CO}_{2}$ over a Co-modified $\mathrm{Cu}$ (100) surface: A DFT study. J. Chem. Phys. 2016;145:134701.

51. Ziganshin AM, Liebetrau J, Pröter J, Kleinsteuber S. Microbial community structure and dynamics during anaerobic digestion of various agricultural waste materials. Appl. Microbiol. Biotechnol. 2013;97:5161-5174.

52. Gulhane M, Pandit P, Khardenavis A, Singh D, Purohit H. Study of microbial community plasticity for anaerobic digestion of vegetable waste in Anaerobic Baffled Reactor. Renew Energy 2017;101:59-66.

53. Qiu G, Song YH, Zeng P, Duan L, Xiao S. Characterization of bacterial communities in hybrid upflow anaerobic sludge blanket (UASB)-membrane bioreactor (MBR) process for berberine antibiotic wastewater treatment. Bioresour. Technol. 2013;142:52-62.

54. Kaakoush NO. Insights into the role of Erysipelotrichaceae in the human host. Front Cell. Infect. Microbiol. 2015;5:84.

55. Stolze Y, Zakrzewski M, Maus I, et al. Comparative metagenomics of biogas-producing microbial communities from production-scale biogas plants operating under wet or dry fermentation conditions. Biotechnol. Biofuels 2015;8:8.

56. Fleissner CK, Huebel N, El-Bary MMA, Loh G, Klaus S, Blaut M. Absence of intestinal microbiota does not protect mice from diet-induced obesity. Br. J. Nutr. 2010;104:919-929.

57. Gossett JM, Belser RL. Anaerobic digestion of waste activated sludge. J. Environ. Eng. Division 1982;108:1101-1120.

58. Pavlostathis SG, Giraldo-Gomez E. Kinetics of anaerobic treatment: a critical review. Crit. Rev. Environ. Sci. Technol. 1991;21:411-490.

59. Cheng S, Logan BE. Sustainable and efficient biohydrogen production via electrohydrogenesis. Proc. Natl. Acad. Sci. 2007;104: 18871-18873.

60. Pelletier E, Kreimeyer A, Bocs S, et al. Candidatus Cloacamonas acidaminovorans: genome sequence reconstruction provides a first glimpse of a new bacterial division. J. Bacteriol. 2008;190:2572-2579.

61. Limam RD, Chouari R, Mazeas L, et al. Members of the uncultured bacterial candidate division WWE1 are implicated in anaerobic digestion of cellulose. Microbiol. Open 2014;3: 157-167. 